\title{
A Systematic Review of the Literature on the Use of Rational Emotive Behaviour Therapy in Criminal Justice Work to Reduce Re-offending
}

\author{
Mia Debidin · Windy Dryden
}

Published online: 14 April 2010

(C) Springer Science+Business Media, LLC 2010

\begin{abstract}
A systematic review of the published literature from 1995 to 2007 considers the published evidence on the use of interventions employing Rational Emotive Behaviour Therapy in criminal justice efforts to reduce re-offending. Thirty-six studies are briefly described, summarised and appraised for research quality using a six point scale. Twenty-four studies were excluded from further analysis due to insufficiently rigorous or weak research design and method. Twelve studies were appraised as sufficiently robust to reliably inform the research interest. Further analysis of the studies indicated an association between negative emotional states and offending behaviour, some evidence of REBT effectiveness in treating emotional disturbance in offender populations, and mixed evidence of REBT effectiveness in reducing re-offending. It is concluded that interventions using REBT might be a promising approach for aiding criminal justice aims to reduce re-offending.
\end{abstract}

Keywords Systematic review $\cdot$ Criminal justice $\cdot$ Re-offending $\cdot$ REBT

\section{Introduction}

One of the key public service agreements of the National Offender Management Service in the Ministry of Justice, England and Wales, is to reduce further offending

This research was conducted as part of the requirements for the MSc in REBT at Goldsmiths University of London. The views expressed are those of the authors, not necessarily those of the Ministry of Justice, nor do they reflect government policy.

M. Debidin $(\bowtie)$

Ministry of Justice, London, UK

e-mail: miadebidin@gmail.com

W. Dryden

Goldsmiths University of London, London, UK 
of offenders processed by the criminal justice system (Home Office 2002). To this end, the service has taken different approaches to reducing and preventing crime, including the use of interventions designed to rehabilitate and resettle offenders dealt with in custody by HM Prison Service and supervised in the community by the National Probation Service. Amongst the rehabilitative interventions used, those based on the theory and practice of cognitive behaviour therapy (CBT) are heralded as the most effective for producing an outcome of reduced re-offending (Vennard et al. 1997).

A relatively recent Home Office publication summarised current knowledge of what works to reduce re-offending and concluded that the few rehabilitative programmes in use nationally, that had been subject to evaluation, produced mixed evidence of effectiveness in England and Wales (Debidin and Lovbakke 2005). The question of 'what works with whom, to reduce re-offending?' remains open to exploration for as long as existing answers indicate that there is still much to be tried, tested and known. There is value in examining different approaches to determine what contribution they might make, if any, towards achieving criminal justice aims to reduce re-offending. In the case of programmes based on cognitive behavioural approaches, it might prove useful to know if Rational Emotive Behaviour Therapy (REBT), which uses both cognitive and behavioural methods, produces a desired effect. Such knowledge might be of value in determining the training and practice of those charged with managing and rehabilitating offenders within the National Offender Management Service. It might also be of value in determining how best to manage the problems of emotional well being and thinking problems found as prevalent criminogenic needs with a large proportion of offenders in England and Wales. ${ }^{1}$ Profiles of offenders in both custodial and community settings show that $58 \%$ of those assessed had a problem of emotional well-being, while $61 \%$ had problems with thinking (Howard 2006).

The purpose of the research reported here was to summarise the published literature on interventions employing Rational Emotive Behaviour Therapy in criminal justice efforts to reduce re-offending, by applying the method of a systematic review of the literature to determine the current state of knowledge.

In deciding how far back to review the literature on this subject, a useful starting point was suggested by the existence of a special mini-series edition of the Journal of Rational-Emotive \& Cognitive-Behaviour Therapy published in 1995 which focused on psychotherapeutic practice of Rational Emotive Behaviour Therapy (REBT) and Cognitive Behaviour Therapy (CBT) with offender populations. The contents of that journal are summarised briefly here as a further introduction to the research described in this report.

The editor introduced the mini-series with the suggestion that offenders benefited from REBT in two stages: Firstly, from learning the ABC model which shows the mediating role of beliefs in response to activating events, to determine emotional, behavioural and cognitive consequences. Secondly, through challenging irrational thinking and adopting "more rational appraisals of reality" (Bernard 1995, p. 212).

\footnotetext{
${ }^{1}$ Criminogenic needs are problems, usually of a changeable nature, that are associated with offending and implicated as possible causes and targets of treatment (Andrews and Bonta 1998).
} 
One of the contributors to the mini-series, who had raised the question of how well REBT explained the anti-social behaviour of the offender population as well as it did emotional disturbance, was invited to outline thoughts on the connection between irrational beliefs and disordered behaviour.

In the first article, entitled Power and Control in the Male Antisocial Personality, Nauth (1995) hypothesised a connection between antisocial behaviour and the irrational belief "I must have control", and used this to explain both aggressive behaviour and opposition to authority as resulting in efforts to maintain control. The author also claimed that REBT was ideally suited to therapeutic work with offenders in teaching them the role of beliefs in generating emotional distress and poorly adjusted behaviour, and thereby encouraging them to accept responsibility for and exercise control over their own thoughts, feelings and behaviours.

While Nauth used examples from specific cases to illustrate her suppositions and also referred to two empirical studies that indicated some support of her hypothesis, the causal relationship between irrational beliefs and offending behaviour was not clearly evidenced nor had the supposed treatment effect of REBT been rigorously tested. At best, the author pointed to the need for empirical study to examine the hypothesised connection between an irrational demand for control and offending behaviour.

The second article in the mini-series addressed The Practice of Rational Emotive and Cognitive Behaviour Therapy with Offenders (Altrows 2005) and began by noting Ellis' recommendations on working with the criminal personality. These were to: "change the basic thinking of the offender in the direction of diminishing absolutistic thinking, increasing long range hedonism and increasing self-acceptance" (Ellis 1985, cited in Altrows 1995 p. 225).

Altrows also noted at the time that there was an increasing body of empirical literature on REBT and CBT with offenders and that much of it provided evidence for the notion that cognitions, including irrational beliefs, play an important part in mediating criminal activity. This idea was further supported by other evidence explaining models of aggression.

In his article, Altrows (1995) also suggested that cognitive therapies might decrease unpleasant emotions such as guilt or anxiety and thereby undermine motivation to offend or decrease the risk of re-offending. Reference to one study lent some support to Altrows claims for the significance of negative emotional states amongst offenders.

The third article in the series dealt with the practical issues of REBT in a forensic setting, and provided a mainly descriptive account of the prison environment based on the author's experience. Kopec (1995) claimed that REBT was an effective therapy to use with the offender population because of its active directive style, and because it dealt with practical problems in the present and provided solutions. She claimed that REBT provided offenders with a new mechanism of coping that they could incorporate into other areas of their lives. Much of what she described was anecdotally based on her own experience, including the finding that pragmatic disputation worked more effectively than other types of disputation with an inmate population. Her conclusions that REBT was an effective treatment to use in a 
forensic setting, for enabling inmates to overcome the hassles, stresses and frustrations of life were not supported with reference to any empirical evidence.

The fourth article in the series, Rational Cognitive Therapy with Public Offenders, briefly presented an illustrative case of a variation of REBT, described as a simplified version for the offender population. This method aimed to "provide offenders with a method for understanding and alleviating unhelpful emotional reactions" (Smith and Lombardo 1995 p. 256). The authors reasoned that, based on a reported finding (for which details were not provided) of the problems that faced 9 out of 10 offenders, that teaching offenders how to relate better to people and how to manage their money and leisure time more effectively, seemed logical steps to helping offenders to adjust. Smith and Lombardo did not explain how their varied version of REBT would achieve this end or any evidence that their assumption of a need for a simplified version was justified. Moreover, they provided only anecdotal evidence of the effectiveness of their approach with 'public offenders'.

The fifth article in the series described the Identification of Adolescent Sexual Offenders: A REBT Model (Seasock 1995). The author emphasised the importance of assessing perceptions, inferences and beliefs in distinguishing between the adolescent sexual offender and the adolescent who commits inappropriate sexual behaviour. He reported that low frustration tolerance and demandingness appeared to be the most commonly found irrational beliefs amongst adolescent sexual offenders in his programme.

Based on his experience, and illustrated with one example, the author claimed that the presence or absence of dysfunctional cognitive processes, was best established by using the theoretical concepts of REBT. He claimed that practitioners proficient in the use of REBT in this way, would "develop more appropriate clientcentred treatment strategies that in turn would show greater success rates in the therapeutic process" (Seasock 1995 p. 267). He also claimed that, based on his personal experience, the use of REBT "greatly decreases if not eliminates the possibility of recidivism" (p. 272). However, no empirically derived evidence of any of his claims was reported.

The sixth and final article in the series considered the Uses of Rational Emotive Behaviour Therapy with Juvenile Sex Offenders (Whitford and Parr 1995). The authors described their use of REBT since 1985 as a "core treatment tool" in their work with sex offenders and noted that its effectiveness was "demonstrated in the reduction of emotional disturbance and/or negative mood states that are often the precursor to the deviant cycle of sexual abuse". They described the prevalence of low frustration tolerance and poor impulse control amongst many of their juvenile sex offenders.

After describing the therapeutic approach, they reported that the practice of REBT methods led to maladaptive behaviour, emotions and beliefs being dramatically reduced, while self-efficacy increased. They also claimed that in their experience, REBT group treatment reduced juveniles' sex offending and thereby, reduced sexual abuse in the community (Whitford and Parr 1995). They expressed concern that programme effectiveness would be impaired if offenders who developed an REBT outlook were then placed amongst rehabilitative caregivers with irrational and emotionally disturbed ways. There is some irony in the fact that 
the authors offered no empirically derived evidence to support their claims, and concluded with the observation that "research and outcome studies on the assessment and treatment of juvenile sex offenders leave much to be desired. There is much work to be done and reported by competent clinicians" (Whitford and Parr 1995 p. 282).

The conclusions to be drawn from the mini-series special edition of the journal on the application of REBT with offenders did not provide any rigorously obtained evidence of its effectiveness in changing re-offending or any other outcomes. At best, it highlighted several theories about the use of REBT with offenders that had not yet then been empirically tested. The question of what REBT might contribute to criminal justice efforts to reduce re-offending had not even begun to be sufficiently addressed in the special edition of the journal.

A brief review of the few articles cited in the journal of empirical research on REBT with offenders conducted prior to 1995 indicated that these earlier studies also lacked rigour in being similarly based on anecdote (e.g. Nauth and Edwards 1988), using very small sample sizes and weak evaluation design (e.g. Solomon and Ray 1984). However, reference was made to much more rigorous pieces of research, including for example longitudinal studies (Marques et al. 1994), studies employing experimental design (Jenkins-Hall 1994), and the seminal work of Yochelson and Samenow (1977) on The Criminal Personality which concluded that the approach to eliminating criminal thinking processes was related to reality therapy and rationalemotive therapy.

The current research considers that the question might be best answered with reference to:

(a) robust evidence of the need for an intervention that deals with emotional disturbance or irrational beliefs in offender populations.

(b) robust evidence of the effectiveness of interventions using REBT, in changing offending behaviour.

This evidence was sought using the method of systematic review of the literature instead of through evaluative research using experimental design.

\section{Method}

The method of systematic review departs from narrative reviews by systematically categorising the standard of previous research according to the methods used, without reliance on unstructured description or reporting of statistical findings (Davies and Crombie 2001). The present study was a qualitative rather than a quantitative (or meta-analytic study), and effect sizes were not considered.

\section{Search Process and Restrictions}

This literature review was limited to published literature listed in library databases, and the search was restricted to literature containing search terms relevant to the research interest. 
The first search used the terms: Rational Emotive Therapy (RET), Rational Emotive Behaviour ${ }^{2}$ Therapy (REBT), Cognitive Behavioral Therapy (CBT) AND: Offenders, Offending, Crime, Criminals, Rehabilitation, Re-offending, Prisoners, Prisons, Probation Probationers, Corrections, Correctional Services, Forensic, Desistance, Deterrence, Dangerous.

The second search used the terms: emotions, feelings, emotional states, AND Offenders, Offending, Crime, Criminals, Re-offending, Desistance.

The search parameters were set from 1995 to 2007 using English language journals only. The search was done using two databases. The first was Psychlit/ PsycInfo, which is a database and search engine of psychological literature from the 1800 s to the present, with coverage of over 1,900 journals and publications in psychology, psychiatry, neuropsychology and neuroscience. It includes, for example, the Journal of Cognitive and Behavioural Psychotherapies, the Journal of Rational-Emotive \& Cognitive Behaviour Therapy, Journal of Quantitative Criminology, Journal of Social and Clinical Psychology.

The second database used was the National Criminal Justice Reference Service (NCJRS) which has a large criminal and juvenile justice library covering publications from the 1970 s to the present and containing over 185,000 publications, reports and articles from around the world. It covers, for example, Crime and Delinquency, Criminal Justice and Behaviour, Criminology, Journal of Behaviour Therapy and Experimental Psychiatry, Journal of Addictions and Offender Counseling.

Abstracts were obtained for all results produced from the initial searches and these were read to check relevance to the research question. All abstracts that appeared relevant to offenders and therapeutic treatment using REBT were retained and the full text article was obtained where the subject was clearly research as opposed to an instruction manual or practitioner's guide. All studies retained for analysis involved some use of REBT. ${ }^{3}$ As the main focus of interest was on the outcome of re-offending, studies were excluded which referred only to outcomes of substance misuse or abuse, even where the intervention involved CBT methods relevant or similar to methods used in REBT. ${ }^{4}$ Other excluded studies included those focused solely on describing the process of therapy with no claims made about outcomes, and studies about offending without reference to therapeutic interventions.

The retrieved research articles were read and summarised in a Table 1 noting the year and authors of the study, the study type or research design used, details of sampling, findings and conclusions, a descriptive appraisal of the research quality and a numerical rating of the research quality. The appraisal rating is described below. The table of findings is included in the results section of this report.

\footnotetext{
$\overline{2}$ Both the American and British spellings of behavior and behaviour were used.

3 This includes studies of interventions that do not appear to use REBT, but are known to by the first author who was trained in the use of them.

${ }^{4}$ In effect, several studies referred to the treatment of drug-related problems based on principles of cognitive behavioural theory but no studies referred specifically to REBT or related CBT methods.
} 


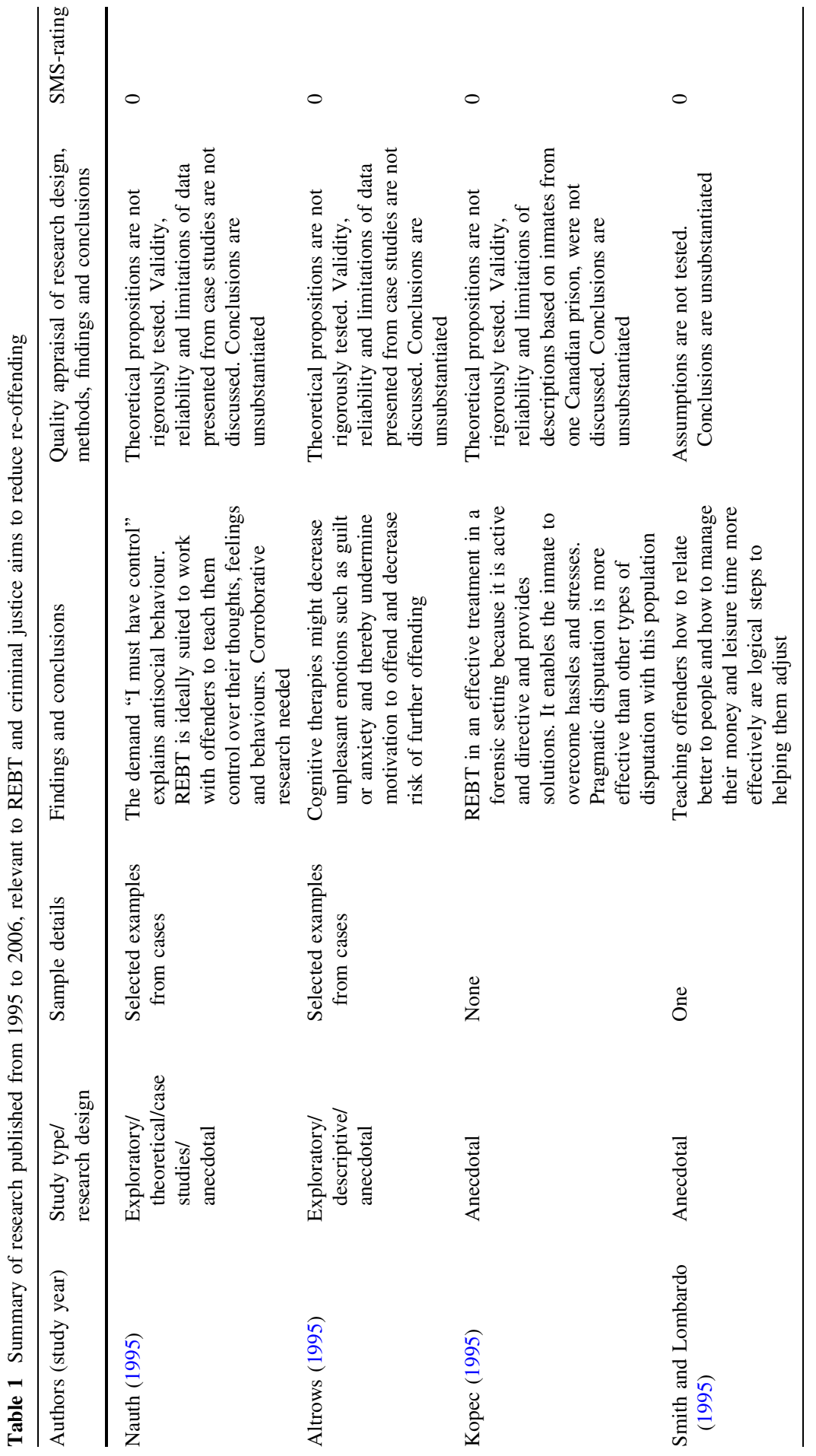




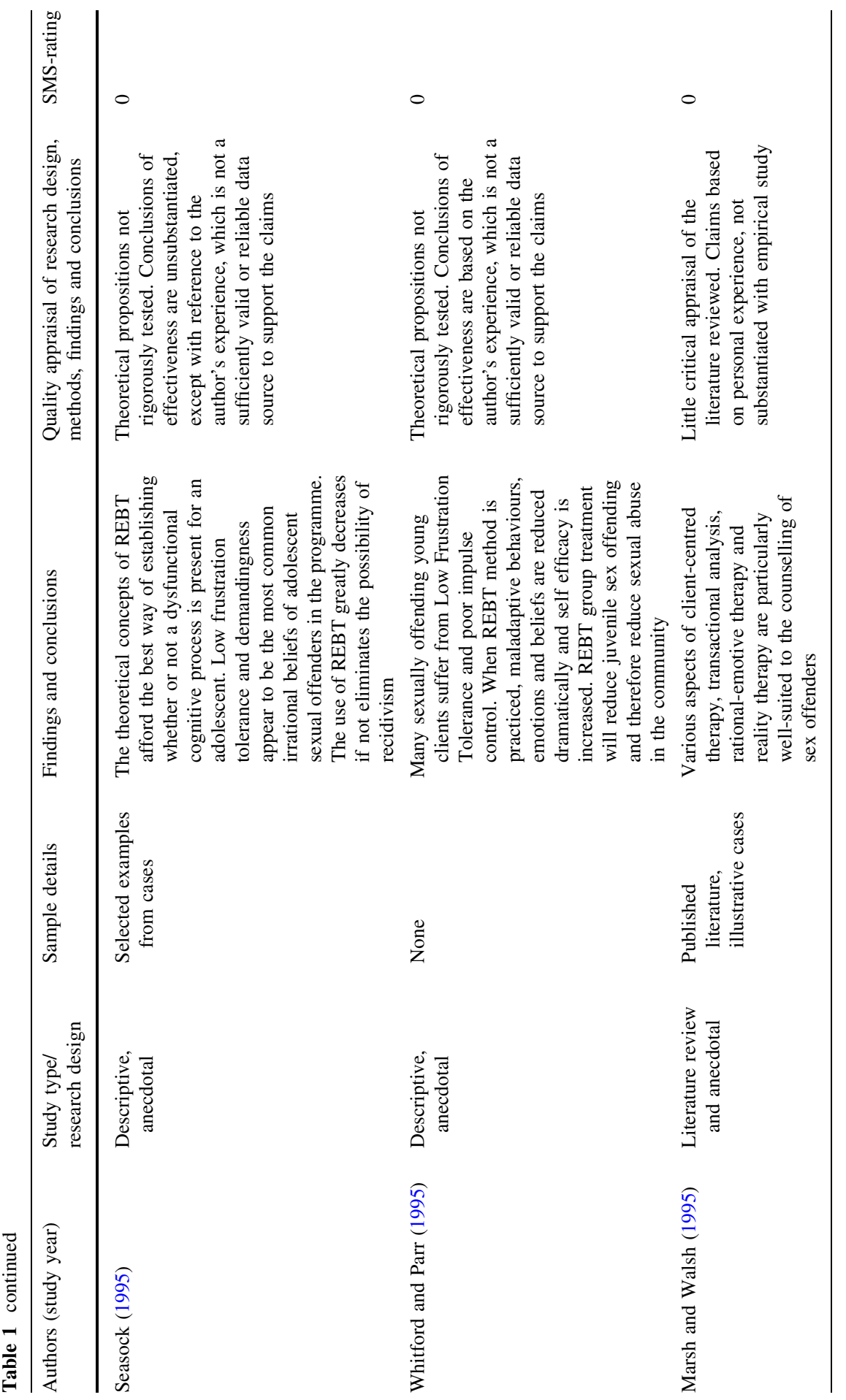




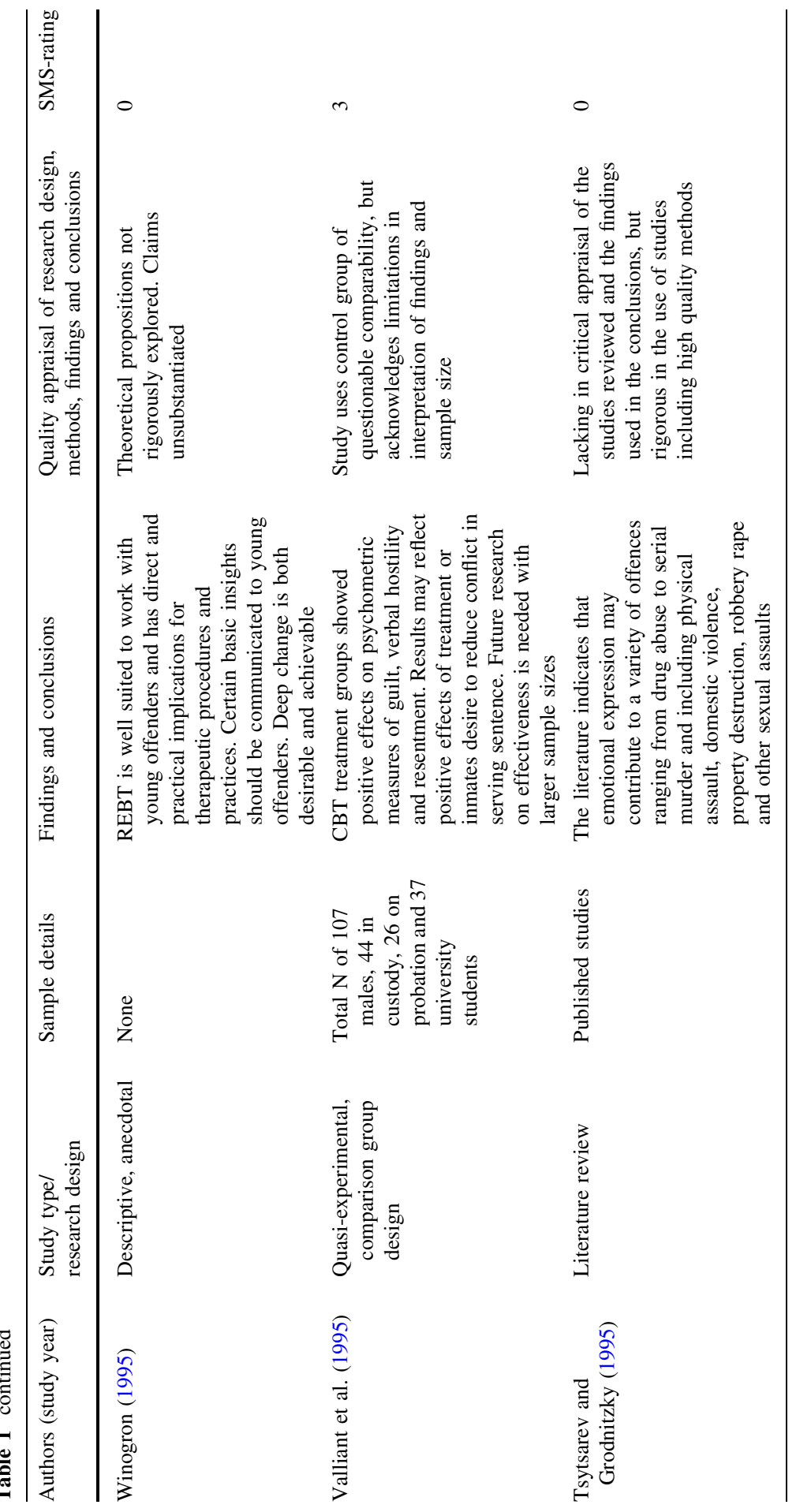




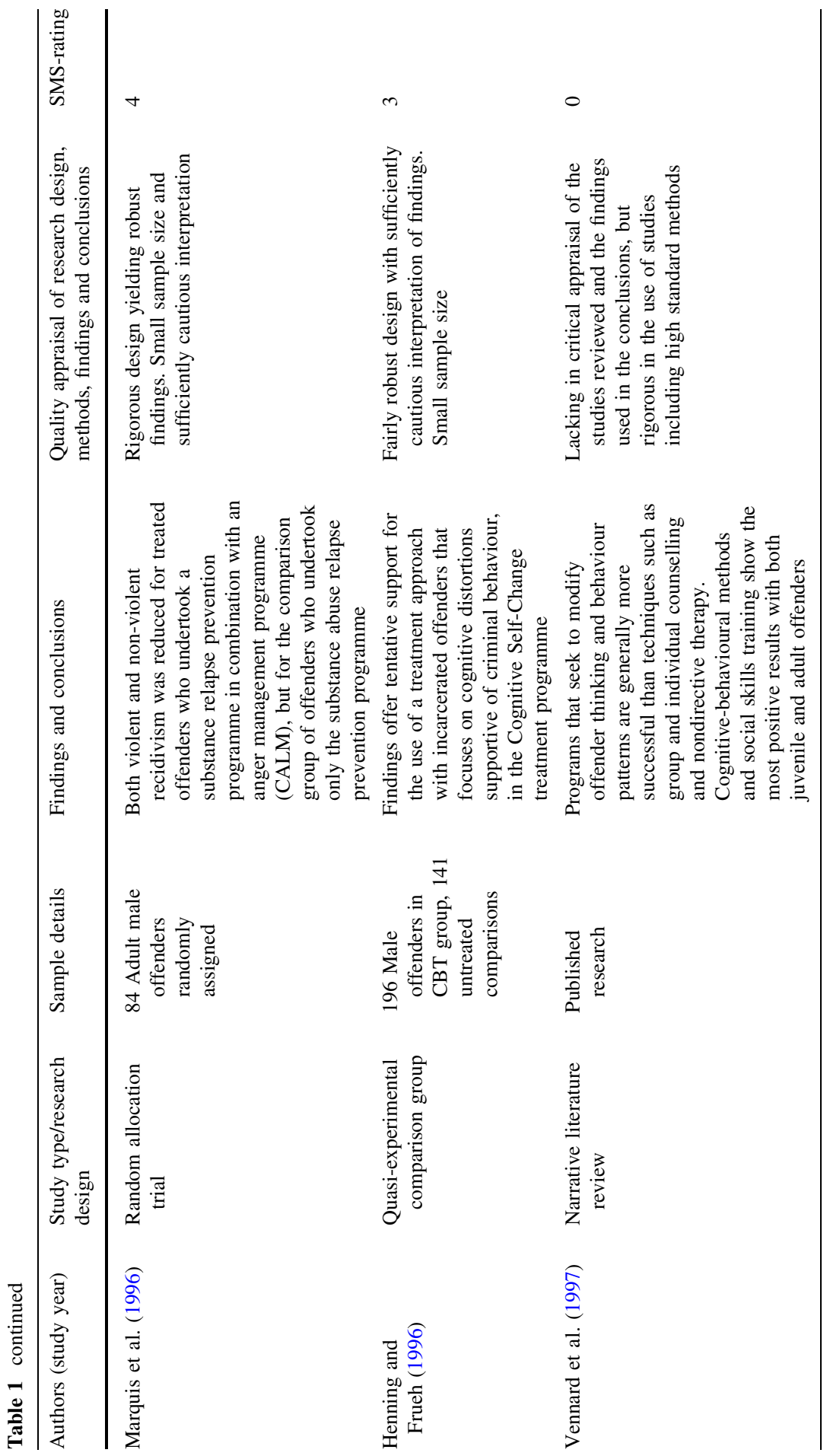




\begin{tabular}{|c|c|c|c|}
\hline & $N$ & $\forall$ & $m$ \\
\hline 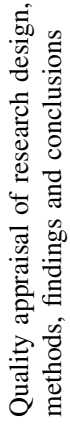 & 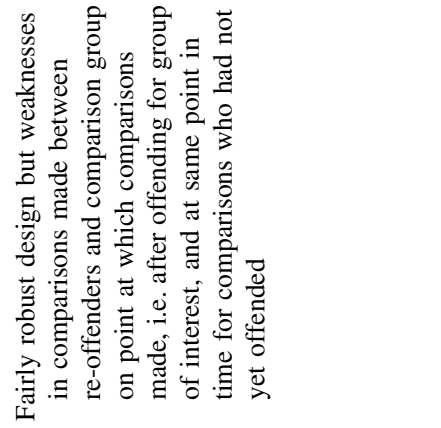 & 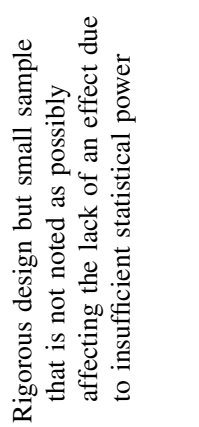 & 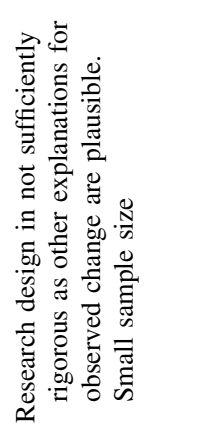 \\
\hline 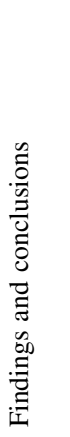 & 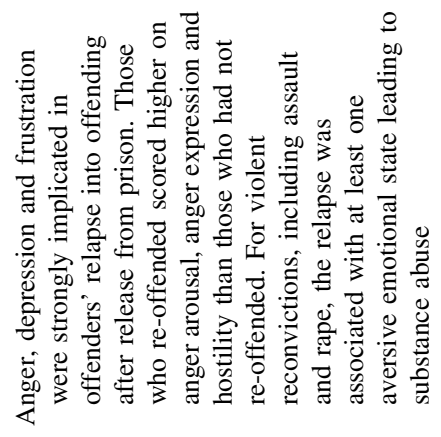 & 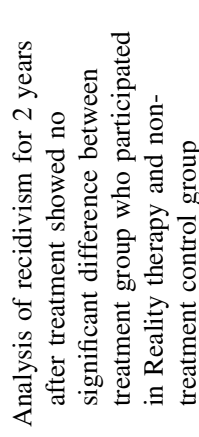 & 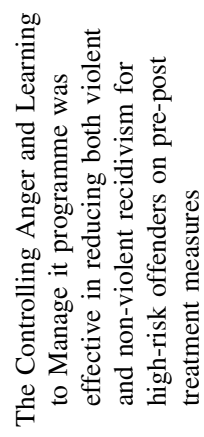 \\
\hline 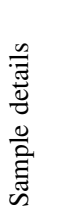 & 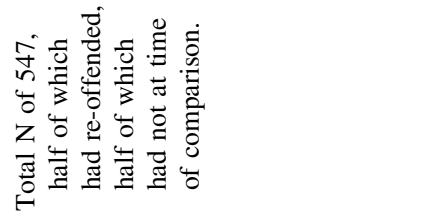 & 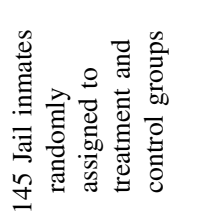 & 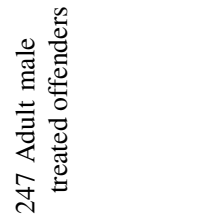 \\
\hline 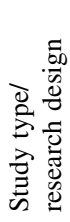 & 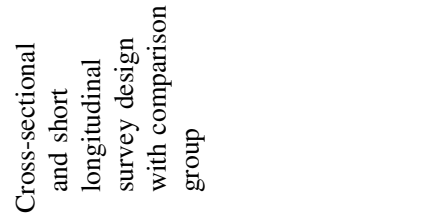 & 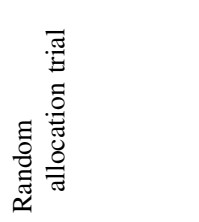 & 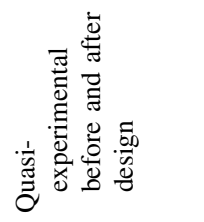 \\
\hline 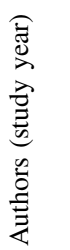 & 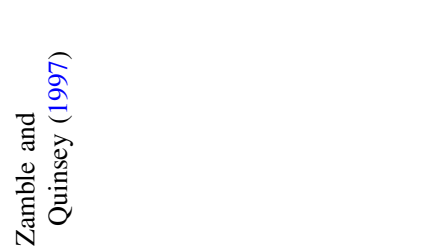 & 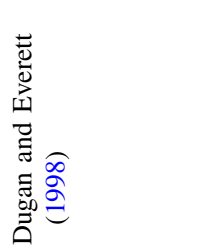 & 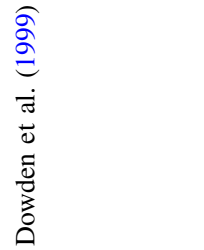 \\
\hline
\end{tabular}




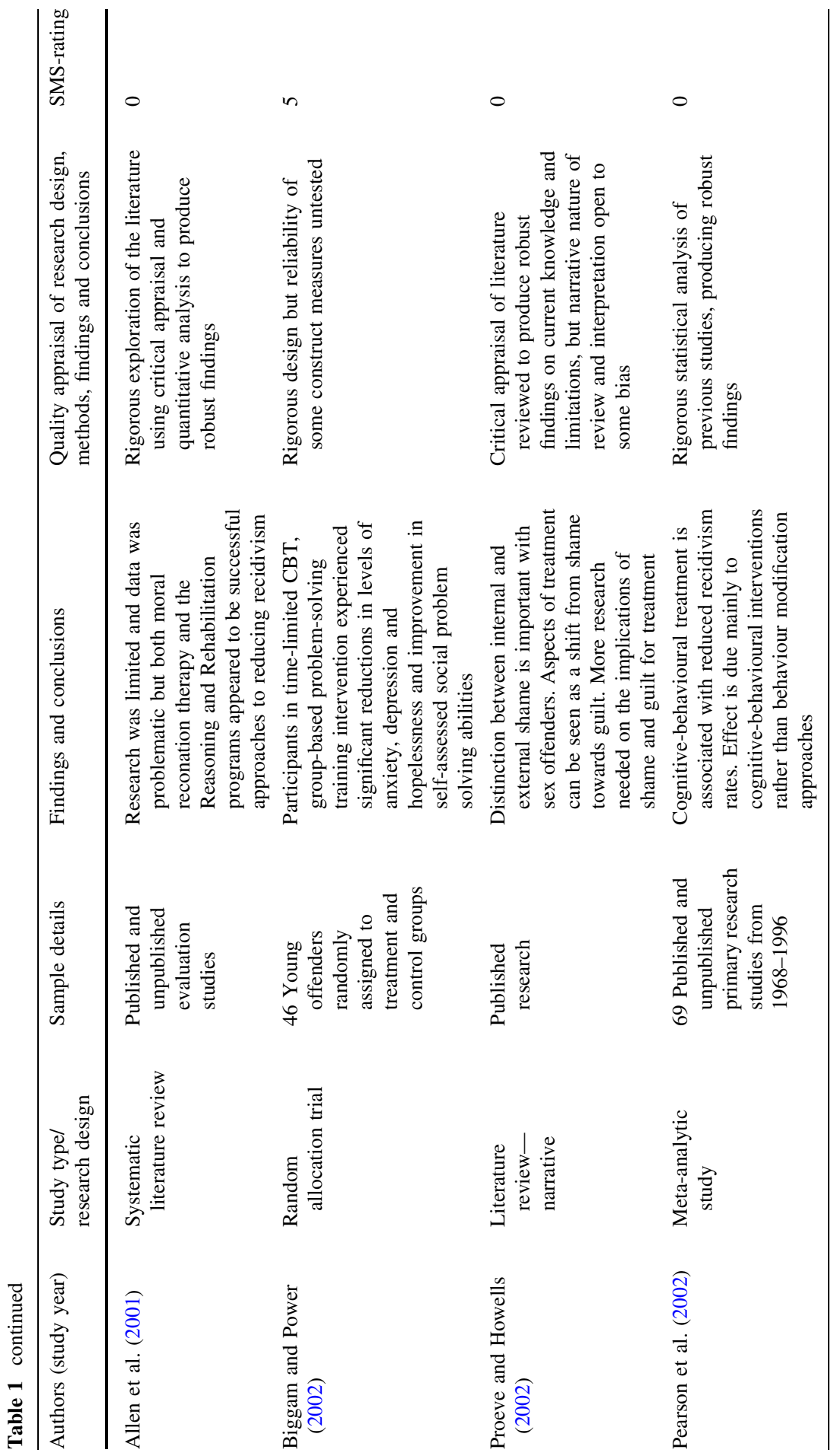




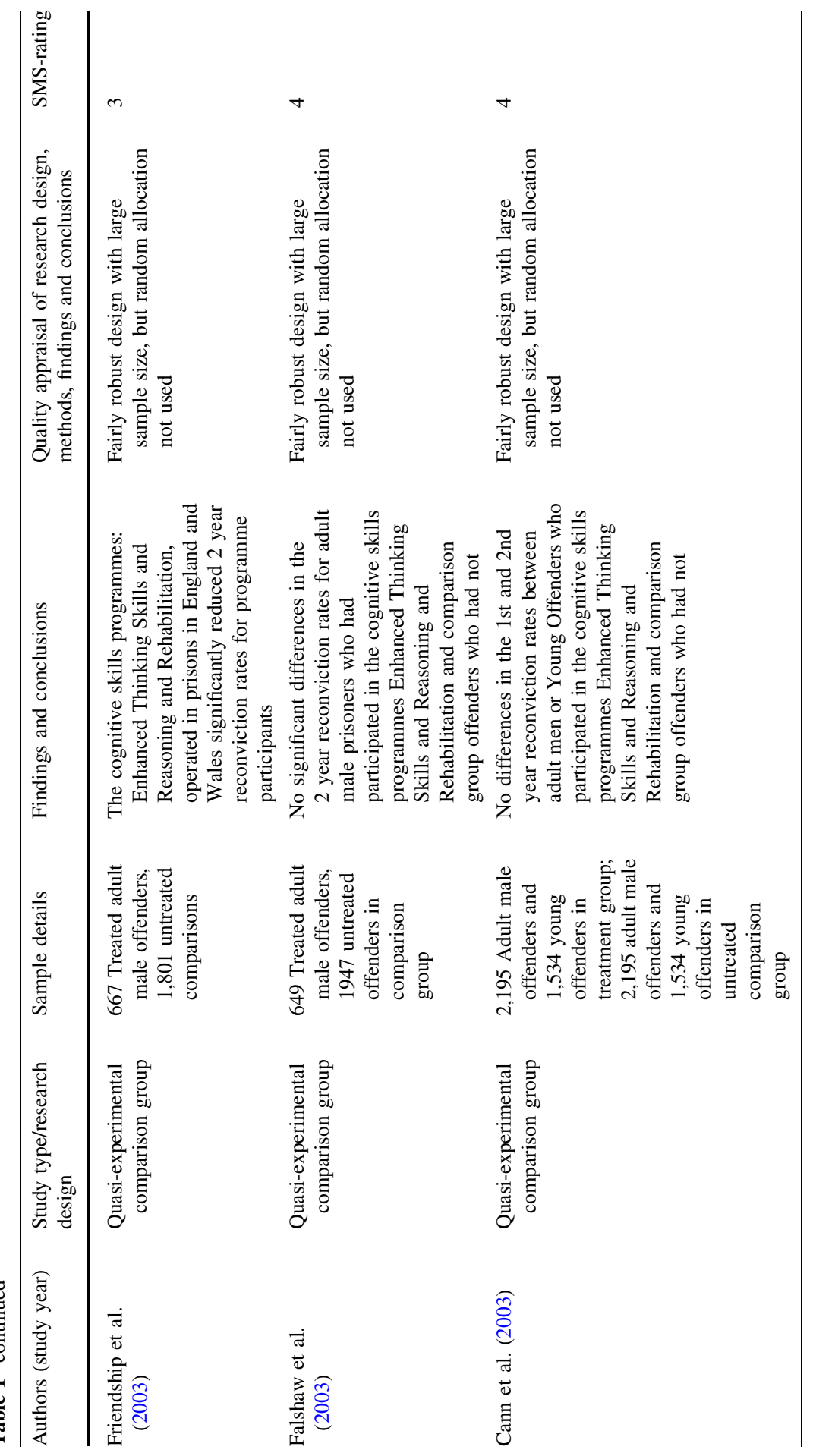




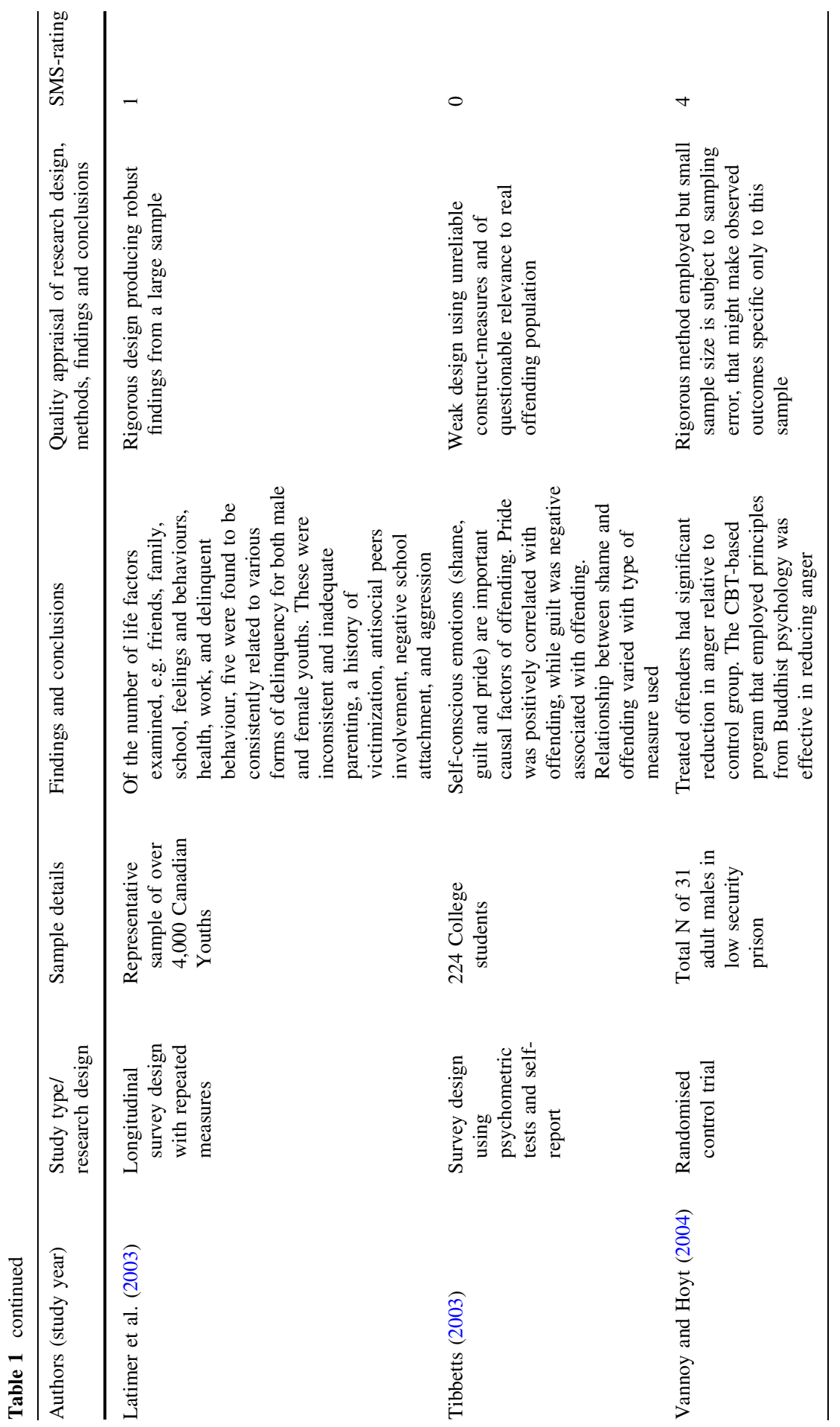




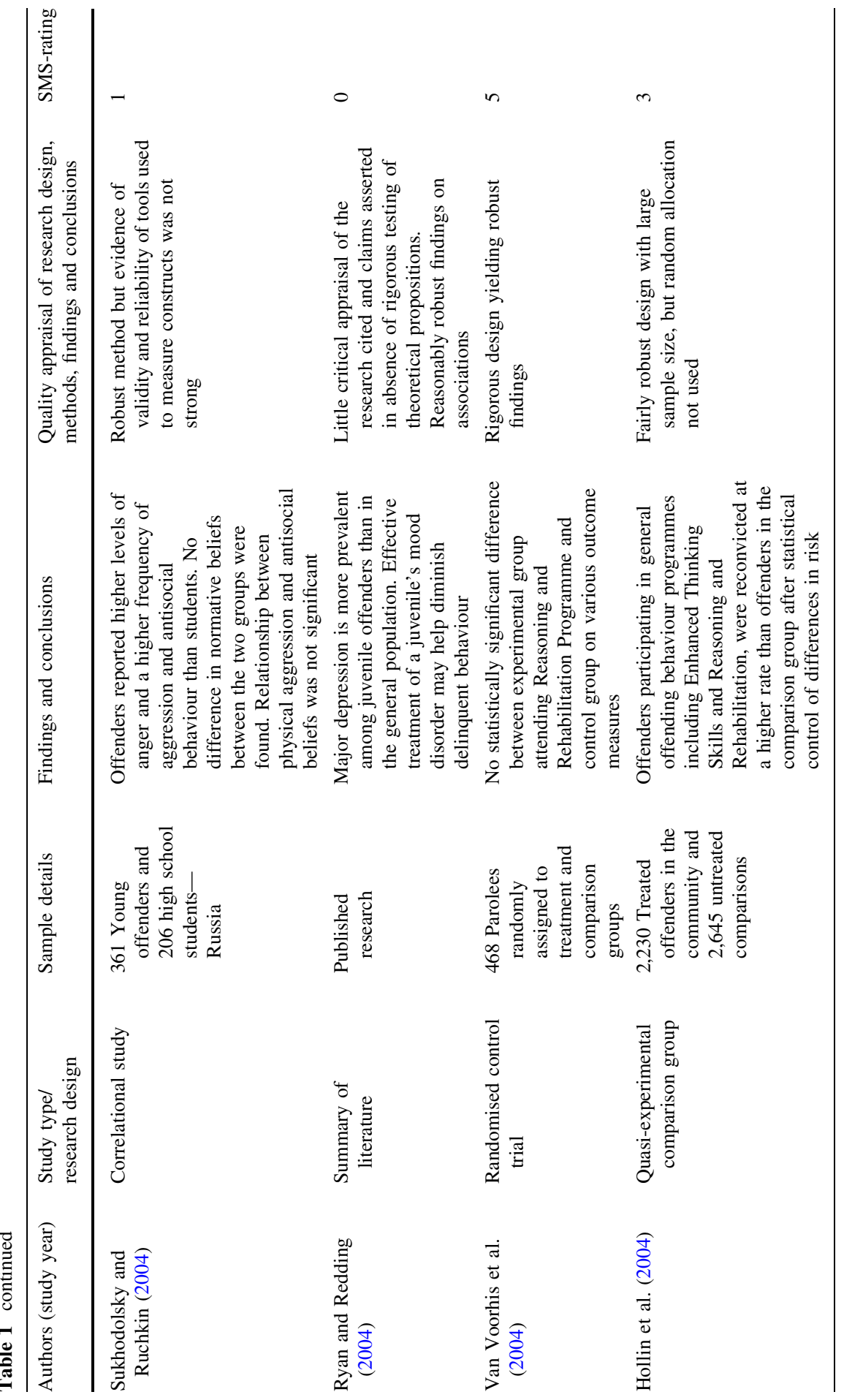




\begin{tabular}{|c|c|c|c|c|}
\hline & - & 0 & 0 & - \\
\hline 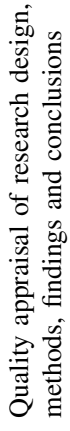 & 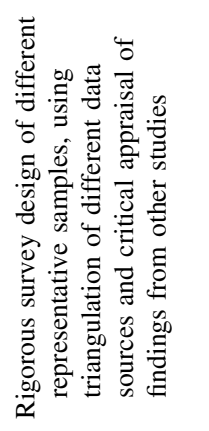 & 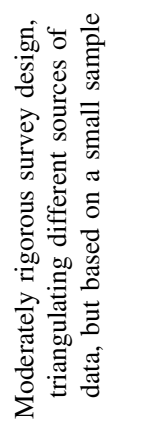 & 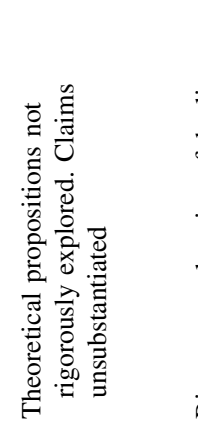 & 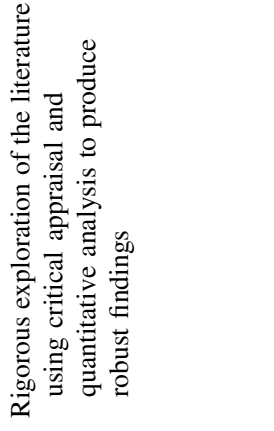 \\
\hline 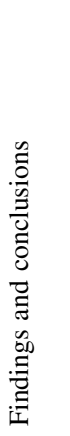 & 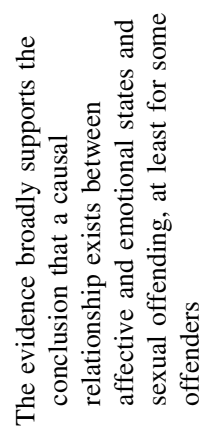 & 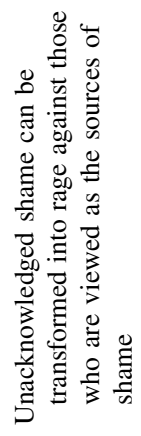 & 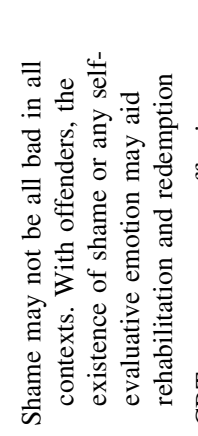 & 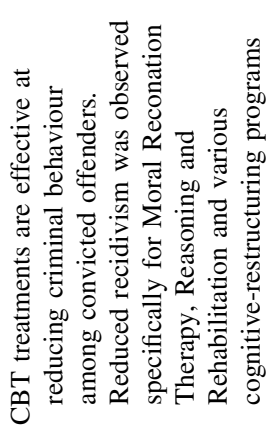 \\
\hline 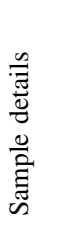 & 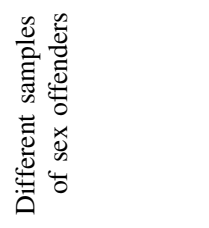 & 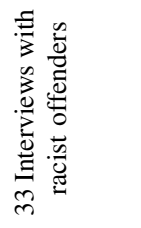 & 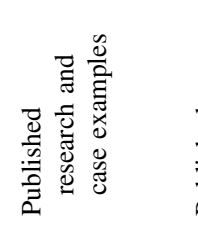 & 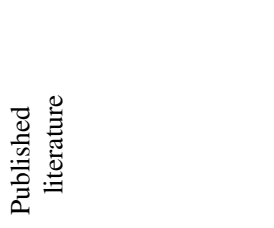 \\
\hline 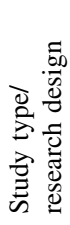 & 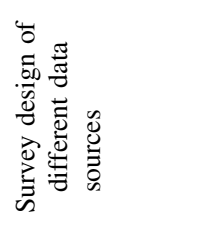 & 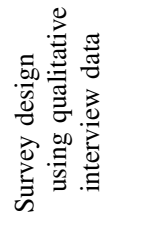 & 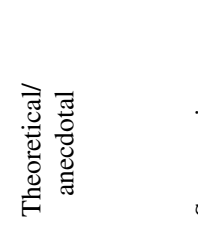 & 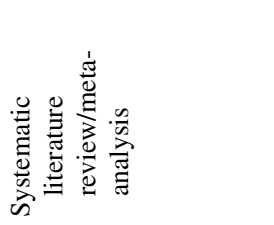 \\
\hline 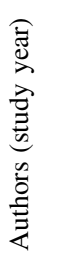 & 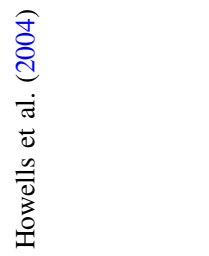 & 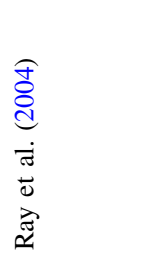 & 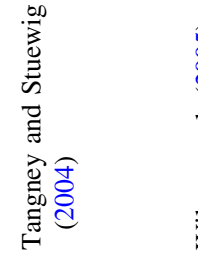 & 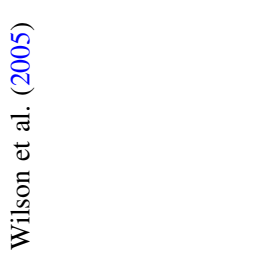 \\
\hline
\end{tabular}




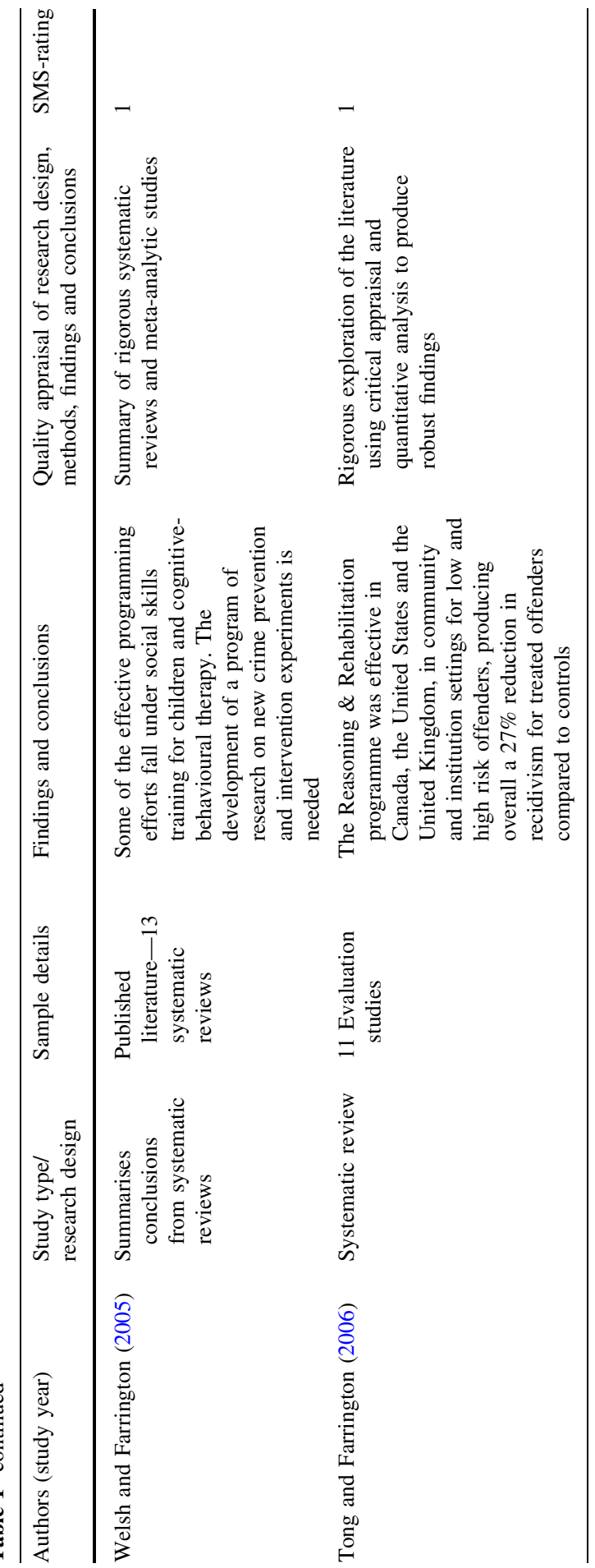




\section{Appraisal of Research Quality}

A slightly extended version of the Maryland Scientific Methods Scale (SMS; Sherman et al. 2002) was used in this research. The SMS is used to evaluate the reliability of the effects of criminological interventions based on the methodological quality of the study design, using a five point scale. ${ }^{5}$ It has been used in a number of criminal justice studies to appraise research quality (Harper \& Chitty 2005). This research extended the five point scale to include a zero rating for methods that are not suited to evaluation research. The full scale is described in the table below.

\section{Maryland Scale}

\begin{tabular}{|c|c|c|}
\hline Study design and rating & Score & Description of rating \\
\hline $\begin{array}{l}\text { Design or method not suited to } \\
\text { evaluation }\end{array}$ & 0 & $\begin{array}{l}\text { Reporting of anecdotal findings, selective case study } \\
\text { material, narrative or systematic literature reviews } \\
\text { only, absence of any empirical aspect to the research, } \\
\text { and reporting of theoretical exposition }\end{array}$ \\
\hline Correlational study & 1 & $\begin{array}{l}\text { Reporting of a correlational coefficient denoting the } \\
\text { strength of the relationship between a particular } \\
\text { intervention and its effectiveness in preventing } \\
\text { reoffending at a given point in time }\end{array}$ \\
\hline Pre and post test with no control group & 2 & $\begin{array}{l}\text { Reporting of a comparison group present, but this might } \\
\text { lack comparability to the target group. Alternatively, } \\
\text { where no comparison group is present, before-and-after } \\
\text { measures (of offending behaviour, for example) have } \\
\text { been obtained for the target group }\end{array}$ \\
\hline $\begin{array}{l}\text { Observational cohort study with } \\
\text { comparable group/quasi- } \\
\text { experimental }\end{array}$ & 3 & $\begin{array}{l}\text { Reporting of a controlled experimental design with } \\
\text { comparable target and control groups present, with pre- } \\
\text { and-post comparisons being made and experimental- } \\
\text { control comparisons on (a) specific variable/s }\end{array}$ \\
\hline Quasi-experimental/controlled trial & 4 & $\begin{array}{l}\text { Reporting of a controlled experimental design, as in (3) } \\
\text { above, but with additional controlling for other } \\
\text { variables that might pose a threat to the interpretations } \\
\text { of the results. Examples of controlling extraneous } \\
\text { variables include, but are not limited to, the use of } \\
\text { statistical procedures or matching }\end{array}$ \\
\hline Randomised control trial & 5 & $\begin{array}{l}\text { Reporting of a fully randomised experimental design in } \\
\text { which target and control groups consists of randomly } \\
\text { assigned individuals and appropriate measures are } \\
\text { taken to test for the effects of the intervention }\end{array}$ \\
\hline
\end{tabular}

Only those studies that scored three, four or five for methodological quality were included for further analysis in this research.

All thirty-six studies were rated by the first author of this report and another researcher independently, in order to determine the extent of agreement on the ratings assigned and thereby highlight any potential bias. Thirty-one studies were

\footnotetext{
5 The scale is limited by not further appraising the quality of each type of design or allowing for the possibility of low standards in superior evaluation methods.
} 
given the same rating by both researchers. Five studies showed disagreement by a difference of one point, however, this difference did not affect the category of inclusion for further analysis, for which there was $100 \%$ agreement. A statistical test of inter-rater reliability using the Kappa statistic was performed to determine consistency between the raters. Results showed Kappa $=.73,(p<.001), 95 \%$ CI $(0.56,0.89)$, giving some assurance of consistency in quality appraisal.

\section{Search Results}

The first searches produced 812 publications. Of these, 500 abstracts were selected for further examination. Of the 36 abstracts retained, eight specifically referred to the use of REBT with offenders, ten addressed the relationship between emotional disturbance and offending. Another nineteen were considered even though they did not refer specifically to REBT, because they referred to Cognitive Behaviour Therapy (CBT) with offenders (seven studies), or programmes that combined methods from CBT, REBT, skills training and other models. (Twelve studies ${ }^{6}$ ) In particular, evaluation studies that mentioned the Reasoning \& Rehabilitation Programme (R\&R), the Enhanced Thinking Skills Programme (ETS) and the Controlling Anger and Learning to Manage (CALM) it programme, were retained because all three of these programmes include several sessions on emotional management that draw specifically on the philosophy and methods of Rational Emotive Behaviour Therapy. Additionally, studies that referred to the Cognitive Self Change Programme and Reality Therapy, were also included as interventions that directly employ or draw on methods used in REBT. Over 760 publications listed from the initial searches were not relevant to the research question based on the contents of the publication summary or research abstract and they were not examined any further.

\section{Results}

Table 1 summarises the findings from the research publications examined and appraised in the current research. It is ordered chronologically, and includes all research relevant to answering the question of this. Specifically, (a) evidence of the need for an intervention that deals with emotional disturbance or irrational beliefs in offender populations, and (b) evidence of the effectiveness of interventions using REBT in changing offending behaviour.

The few studies that have reviewed the literature on REBT effectiveness over the years (Lyons \& Woods 1991; Engels et al. 1993; Solomon \& Haaga 1995; Neenan 2001), indicate that the support for REBT as an effective therapeutic intervention is not particularly strong. While some have concluded that REBT is an effective form of therapy when compared to baseline and other forms of control (Lyons \& Woods 1991), and others have discussed the methodological flaws and limitations of REBT evaluation research (Engels et al. 1993; Solomon \& Haaga 1995), the most recently

\footnotetext{
$\overline{6}$ These figures sum to 37 and not 36 because there was some overlap on the subject areas for two studies.
} 
expressed published view is that the empirical evidence in support of REBT continues to be lacking after 45 years (Neenan 2001).

Of the studies reviewed and appraised for research quality, seventeen were rated as ' 0 ', six as ' 1 ', one as ' 2 ', five as ' 3 ', five as '4' and two as ' 5 '. Only the twelve studies with the three highest ratings had their findings and conclusions considered further in this research. It was notable that the studies rated as being of a higher standard were found amongst the more recently published papers, suggesting some improvement over time in the quality of research conducted and published. The better quality studies were not particular to one subject area. Across all of the evidence considered in relation to the points of interest, studies of poor quality and better quality were found.

\section{Discussion}

On the strength of the better quality studies, that is, those rated as ' 3 ', ' 4 ' or ' 5 ', this literature review can offer the following in response to the research questions:

(a) What is the evidence of the need for an intervention that deals with emotional disturbance or irrational beliefs in offender populations?

The evidence moderately indicates an association between negative emotional states such as anger, shame and guilt, and offending behaviour, and therefore the need for an intervention that treats the problems of such emotional states, in addressing offending behaviour, is somewhat supported.

(b) What is for the current state of knowledge about the effectiveness of interventions using REBT, in changing offending behaviour?

There is some evidence that indicates that interventions using REBT may reduce offending behaviour from studies of such programmes that have produced positive treatment effects. However, the findings of a treatment effect varies and it is not possible to determine what specific contribution REBT made to the observed treatment outcomes.

\section{Limitations of the Research}

The findings of this study are limited by the search procedures used, the search terms, the databases searched and the reliance on research published in the English language. The studies retrieved with these methods may be subject to any publication bias that the publishers have toward findings of statistical significance. There is, however, some indication that this may not be the case through the inclusion of published studies that did not find differences of a statistically significant nature.

The narrow range of search terms used may have resulted in the exclusion of other relevant research studies that may have affected the overall findings of this research. Studies which looked specifically at the cognitive and behavioural causes of offending, using a formulation from REBT or CBT were not included. However, 
the use of the key terms of interest can reasonably be expected to have picked up the studies which focused on the subject of interest or made mention of the key terms in the title, abstract, or full text.

Implications for the Practice of Rational Emotive Behaviour Therapy

The main implications for these research findings on the practice of REBT, is that much more needs to be done to test the application and value of REBT with offender populations.

\section{Proposals for Further Research}

1. Further evidence is needed to build on the finding that cognitive-behavioural interventions that combine REBT methods with CBT and social skills training, have produced both favourable and unfavourable results on re-offending. More evaluation is needed of the component parts of such interventions and the effect each therapeutic approach has on the targets of treatment, such as problemsolving, emotional management, and social skills as well as desistance from offending.

2. To build on the finding that the effects of REBT on re-offending are not fully known, it would be necessary to first implement REBT as a therapeutic approach in a criminal justice setting, on a large enough scale to make evaluation using a randomised control trial, a possibility. Offenders would need to be randomly assigned to receive REBT or a non-therapeutic alternative, and the outcomes for each would need to be compared to determine what effect REBT had on re-offending and other outcomes of interest, such as emotionalmanagement, and pro-social behaviour.

\section{Conclusions}

This study set out to consider the published evidence on the use of interventions employing Rational Emotive Behaviour Therapy in criminal justice efforts to reduce re-offending, by considering the evidence from various types of published research relevant to the subject. It found that the evidence indicated a possible need for an intervention that addresses the problems of negative emotional states in offenders, for which REBT may be well suited. It also found mixed evidence in support of the use of REBT as an effective intervention in reducing offending. It can be concluded that REBT might be a promising approach for aiding the criminal justice aims in England and Wales to reduce re-offending, but more work needs to be done to test it out and evaluate its effects.

Acknowledgments With thanks to colleague Debra Dhillon for time given to the task of independently rating the studies. 


\section{References}

*Denotes studies included in the systematic review

*Allen, L. C., MacKenzie, D. L., \& Hickman, L. J. (2001). Effectiveness of cognitive behavioural treatment for adult offenders: A methodological, quality-based review. International Journal of Offender Therapy and Comparative Criminology, 45(4), 498-514.

*Altrows, I. F. (1995). The practice of rational emotive and cognitive behavior therapy with offenders. Journal of Rational-Emotive \& Cognitive-Behavior Therapy Winter, 13(4), 225-242.

Andrews, D. A., \& Bonta, J. (1998). The psychology of criminal conduct (2nd ed.). Ohio: Anderson Publishing Co.

Bernard, M. E. (1995). Rational emotive and cognitive behavioral therapy with offenders: "Teacher Is Happy!" Journal of Rational-Emotive \& Cognitive-Behavior Therapy Winter, 13(4), 211-214.

*Biggam, F. H., \& Power, K. G. (2002). A controlled, problem-solving, group-based intervention with vulnerable incarcerated young offenders. International Journal of Offender Therapy and Comparative Criminology, 46(6), 678-698.

*Cann, J., Falshaw, L., Nugent, F., \& Friendship, C. (2003). Understanding what works: Accredited cognitive skills programmes for adult men and young offenders. Home office research findings 226. London: Home Office.

Davies, H. T., \& Crombie, I. K. (2001). What is a systematic review? www.evidence-basedmedicine.co.uk. Hayward Medical Communications.

Debidin, M., \& Lovbakke, J. (2005). Offending behaviour programmes in prison and probation. In: G. Harper \& C. Chitty (Eds.), The impact of corrections on re-offending: A review of 'what works'. Home Office Research Study 291. London: Home Office.

*Dowden, C., Blanchette, K., \& Serin, R. (1999). Anger management programming for federal male inmates: An effective intervention. Ottawa: Correctional Services Canada Research Branch.

*Dugan, J. R., \& Everett, R. S. (1998). An experimental test of chemical dependency therapy for jail inmates. International Journal of Offender Therapy and Comparative Criminology, 42(4), 360-368.

Ellis, A. (1985). Conceptual thinking and the criminal personality. Journal of Counseling \& Development, 63, 589 cited in Altrows (1995).

Engels, G. I., Garnefski, N., \& Diekstra, R. F. (1993). Efficacy of rational-emotive therapy: A quantitative analysis. Journal of Consulting and Clinical Psychology, 61(6), 1083-1090.

*Falshaw, L., Friendship, C., Travers, R., \& Nugent, F. (2003). Searching for 'What Works': HM Prison Service accredited cognitive skills programmes. The British Journal of Forensic Practice, 6(2), 3-13.

*Friendship, C., Blud, L., Erikson, M, Travers, R., \& Thornton, D. (2003). Cognitive-behavioural treatment for imprisoned offenders: An evaluation of HM Prison Service's cognitive skills programme. Legal and Criminological Psychology, 8, 103-114.

*Henning, K. R., \& Frueh, B. C. (1996). Cognitive-behavioral treatment of incarcerated offenders: An evaluation of the Vermont department of corrections' cognitive self-change program. Criminal Justice and Behavior, 23(4), 523-541.

*Hollin, C., Palmer, E., McGuire, J., Hounsome, J., Hatcher, R., Bilby, C., \& Clark, C. (2004). Pathfinder programmes in the probation service: A retrospective analysis. Home Office Online Report 66/04. London: Home Office.

Home Office. (2002). Spending review 2002: Public service agreements. Chapter 6 Home Office. HMTreasury Website: http://www.hm-treasury.gov.uk/Spending_Review/spend_sr02/psa/spend_sr02_ psahome.cfm.

Howard, P. (2006). The offender assessment system: an evaluation of the second pilot Home Office Research Findings 278. London: Home Office.

*Howells, K., Day, A., \& Wright, S. (2004). Affect, emotions and sex offending. Psychology, Crime \& Law, 10(2), 179-195.

Jenkins-Hall, K. (1994). Outpatient treatment of child molestors: Motivational factors and outcome. Journal of Offender Rehabilitation, 21(1/2), 139-150.

*Kopec, A. (1995). Rational emotive behavior therapy in a forensic setting: Practical issues. Journal of Rational Emotive \& Cognitive-Behavior Therapy Winter, 13(4), 243-254.

*Latimer, J., Kleinknecht, S., Hung, K., \& Gabor, T. (2003). Correlates of self-reported delinquency: An analysis of the national longitudinal survey of children and youth. Canada: Department of Justice. 
Lyons, L. C., \& Woods, P. J. (1991). The efficacy of rational-emotive therapy: A quantitative review of the outcome research. Clinical Psychology Review, 11(4), 357-369.

Marques, J. K., Day, D. M., Nelson, C., \& West, M. A. (1994). Effects of cognitive-behavioural treatment on sex offender recidivism: Preliminary results of a longitudinal study. Criminal Justice and Behavior, 21(1), 28-54.

*Marquis, H. A., Bourgon, G. A., Armstrong, B., \& Pfaff, J. (1996). Reducing recidivism through institutional treatment programs. Forum on Corrections Research, 8(3), 3-5.

* Marsh, R. L., \& Walsh, A. (1995). Physiological and psychosocial assessment and treatment of sex offenders: A comprehensive victim-oriented program. Journal of Offender Rehabilitation, 22(1/2), 77-96.

*Nauth, L. L. (1995). Power and control in the male antisocial personality. Journal of Rational-Emotive \& Cognitive-Behavior Therapy Winter, 13(4), 215-224.

Nauth, L., \& Edwards, K. A. (1988). Teaching rational behaviour to prison inmates. Habilitating a neglected skill. Journal of Correctional Education, 39, 94-96.

Neenan, M. (2001). REBT 45 years on: Still on the sidelines. Journal of rational emotive \& cognitive behaviour therapy, 19(1), 31-41.

*Pearson, F. S., Lipton, D. S., Cleland, C. M., \& Yee, D. S. (2002). The effects of cognitive-behavioural programs on recidivism. Crime and Delinquency, 48(3), 476-496.

*Proeve, M., \& Howells, K. (2002). Shame and guilt in child sexual offenders. International Journal of Offender Therapy and Comparative Criminology, 46(6), 657-667.

*Ray, L., Smith, D., \& Wastell, L. (2004). Shame, rage and racist violence. British Journal of Criminology, 44(3), 350-368.

*Ryan, E. P. D. O., \& Redding, R. E. (2004). A review of mood disorders among juvenile offenders. Psychiatric Services, 55, 1397-1407.

*Seasock, J. P. (1995) Identification of adolescent sexual offenders: An REBT model. Journal of Rational-Emotive \& Cognitive-Behavior Therapy Winter, 13(4), 261-272.

Sherman, L.W., Farrington, D. P., MacKenzie, D. L., \& Welsh, B. C. (2002). Evidence-based crime prevention. New York: Routledge, Taylor and Francis.

*Smith, R. R., \& Lombardo, V. S. (1995). Rational cognitive therapy with public offenders. Journal of Rational Emotive \& Cognitive-Behavior Therapy, 13(4), 255-260.

Solomon, A., \& Haaga, D. A. F. (1995). Rational emotive behaviour therapy research: What we know and need to know. Journal of Rational-Emotive and Cognitive Behaviour Therapy, 13(3), 179-191.

Solomon, G. S., \& Ray, J. B. (1984). Irrational beliefs of shoplifters. Journal of Clinical Psychology, 40(4), 1075-1077.

*Sukhodolsky, D. G., \& Ruchkin, V. V. (2004). Association of normative beliefs and anger with aggression and antisocial behavior in Russian male juvenile offenders and high school students. Journal of abnormal child psychology, 32(2), 225-236.

*Tangney, J. P., \& Stuewig, J. (2004). A moral-emotional perspective on evil persons an evil deeds. In A. G. Miller (Ed.), The social psychology of good and evil. New York: Guildford Press.

*Tibbetts, S. G. (2003). Self-conscious emotions and criminal offending. Psychological Reports, 93(1), 101-126.

*Tong, L. S. J., \& Farrington, D. P. (2006). How effective is the reasoning and rehabilitation programme in reducing re-offending? A meta-analysis of evaluations in three countries. Psychology Crime and Law, 12(1), 3-24.

*Tsytsarev, S. V., \& Grodnitzky, G. R. (1995). Anger and criminality. In H. Kassinove (Ed.), Anger disorders: Definition, diagnosis and treatment. Washington: Taylor and Francis.

*Valliant, P. M., Ennis, L. P., \& Raven-Brooks, L. (1995). Cognitive-behavior therapy model for anger management with adult offenders. Journal of Offender Rehabilitation, 22(3/4), 77-93.

*Van Voorhis, P., Spruance, L. M., \& Ritchey, P. N. (2004). The Georgia cognitive skills experiment: A replication of reasoning and rehabilitation. Criminal Justice and Behavior, 31(3), 282-305.

*Vannoy, S. D., \& Hoyt, W. T. (2004). Evaluation of an anger therapy intervention for incarcerated adult males. Journal of Offender Rehabilitation, 39(2), 39-57.

*Vennard, J., Sugg, D., \& Hedderman, C. (1997). The use of cognitive-behavioural approaches with offenders: messages from the research. Part I. Home Office Research Study No. 171. London: Home Office.

*Welsh, B. C., \& Farrington, D. P. (2005). Evidence-based crime prevention: Conclusions and directions for a safe society. Canadian Journal of Criminology and Criminal Justice, 47(2), 337-347. 
*Whitford, R., \& Parr, V. (1995). Uses of rational emotive behaviour therapy with juvenile sex offenders. Journal of Rational-Emotive \& Cognitive-Behavior Therapy Winter, 13(4), 273-282.

*Wilson, D. B., Bouffard, L. A., \& Mackenzie, D. L. (2005). A quantitative review of structured, group oriented, cognitive-behavioral programs for offenders. Criminal Justice and Behavior, 32(2), 172204.

*Winogron, W. (1995). Correctional psychology with young offenders in the community: Philosophical musings. Forum on Corrections Research, 7(1), 31.

Yochelson, S., \& Samenow, S. E. (1977). The criminal personality. Volume II: The change process. New York: Jason Aronson.

Zamble, E., \& Quinsey, V. L. (1997). The criminal recidivism process. Cambridge: University Press. 